\title{
Outdoor thermal comfort for pedestrians in movement: thermal walks in complex urban morphology
}

\author{
Carolina Vasilikou $^{1,2} \cdot$ Marialena Nikolopoulou ${ }^{3,4}$
}

Received: 19 December 2017 / Revised: 26 July 2019 / Accepted: 5 August 2019 / Published online: 12 September 2019

(C) The Author(s) 2019

\begin{abstract}
In the discussion of designing for a healthier city, people in movement between interconnected spaces perform a non-sedentary activity enhancing sustainability and well-being. However, adverse weather conditions may create uncomfortable thermal sensations that change or ruin the experience of people walking outdoors. This paper is presenting the findings of a 3-year study on the perceptual variation of thermo-spatial conditions and comfort state for pedestrians moving between interconnected spaces. Thermal walks were organised in two European pedestrian routes of 500-m length. The structured walks were conducted with simultaneous microclimatic monitoring and field surveys of thermal perception based on 314 questionnaires, with a focus on the variation of comfort states. The findings suggest that spaces in sequence do not affect significantly microclimatic variation but have a large impact on the dynamic thermal perception of pedestrians. Interconnected spaces of high density result in a differentiation of thermal pleasantness between streets and squares. The aspect of movement along with complexity in urban morphology along a sequence enhances diversity in thermal sensation. This understanding opens possibilities in developing a multisensory-centred urbanism, where the experience of the thermal environment plays an integral role for perception-driven and healthier urban design.
\end{abstract}

Keywords Pedestrian movement · Spatial sequences · Thermal perception · Urban morphology · Environmental diversity · Sensory urbanism $\cdot$ Healthier urbanism

\section{Introduction}

In the discussion of designing for a healthier city, people in movement between interconnected spaces perform a physical activity that promotes both sustainability (as a mode of transport) and well-being (in terms of physical health and social interaction). During this activity, people gather multisensory experiences that inform their state of comfort during their

Carolina Vasilikou

K.Vasilikou@reading.ac.uk

1 Urban Living Research Group, School of Architecture, University of Reading, Reading, UK

2 The Old Library Building, School of Architecture, University of Reading, Reading, Berkshire RG1 5AQ, UK

3 Centre for Architecture and Sustainable Environment, Kent School of Architecture, University of Kent, Canterbury, Kent, UK

4 Marlowe Building, School of Architecture \& Planning, University of Kent, Canterbury, Kent CT2 7NR, UK navigation and wayfinding in the public realm. The latter can be conceived as a series of urban entities (streets, squares, widenings, suks, parks, water surfaces, etc.) that are interlinked in a continuous urban sequence (forming a specific route that is followed by pedestrians). In urban environments that have stood the test of time, such as historic city centres, these interconnected spaces create an intricate sequence of perceptual experiences for people walking. From the interplay of the multiple senses while walking outdoors, this paper focuses on the thermo-spatial environment outdoors and the perceptual variations that occur due to the changes in the urban form as well as the microclimatic conditions at street level. Variations in dynamic thermal perceptions due to a complex urban morphology and its microclimate have not been addressed sufficiently. Following the sensewalking approach (Henshaw et al. 2009), this study is based on the methodology of 'thermal walks' (Vasilikou 2015, 2018) that investigates pedestrian thermal perception through the analysis of the urban climate and spatial morphology. It is formed as a series of focus group walks, where environmental monitoring happened hand-in-hand with people surveys. The new 
methodology focuses on a point-to-point assessment of thermo-spatial variations, combining the collection of objective microclimatic and spatial data with subjective responses by people walking (Vasilikou and Nikolopoulou 2013).

Thermal comfort outdoors is predicted through the model of thermal equilibrium. Although different models for the prediction of outdoor thermal comfort have been developed and used in the design of urban spaces, it is widely recognised that the state of comfort may also be influenced by qualitative parameters that are not included in the models based on the thermal equilibrium (Brager and de Dear 1998). For example, Aljawabra and Nikolopoulou (2009) highlighted the impact of demographic factors (gender, age, culture, economic status); Ait-Ameur (2002) Ng (2012) and Chen and Ng (2012) revealed the contextual parameters (building function, activities, climate, season); Henshaw et al. (2009) and Vasilikou (2018) explored the multisensory and environmental interplay (thermal, aural, visual and olfactory); and Lenzholzer et al. (2017), Lenzholzer and Koh (2010), Lam (2012) and Nikolopoulou and Lykoudis (2007) brought to the surface cognitive parameters (use, behavioural preferences and expectations), all of which play a critical role in the comfort state for people walking. Other research has also demonstrated that in outdoor contexts particularly, where people have limited control over their discomfort, thermal perception is greatly influenced by the information that the person has in a specific setting (Nikolopoulou et al. 2001). The above factors define Baker's (2001) scope for adaptive opportunity and thermal satisfaction outdoors. The latter is dependent on psychological factors (prior experience and time of exposure, etc.; Nikolopoulou et al. 2001) as well as associated expectations and reasoned information (Knez and Thorsson 2006). However, these factors cannot be evaluated solely based on a quantitative approach (Lenzholzer et al. 2017).

Potvin (2000) showed that the sensory experience of the urban continuum is produced in a dynamic state. The sequential nature of interconnected spaces enhances this dynamic perceptual mode through the actual motion between spaces (Ouameur and Potvin 2007). Both studies assert that wind and solar radiation are the main factors attributed for variations in outdoor thermal comfort in any given period, resulting to a wide range of combinations of environmental diversity. The objective to achieve comfort during walking needs to take into account both temporal and spatial variations, as well as opportunities for adaptation. Sensations may include both momentous pleasant and unpleasant experiences. The body in motion itself plays an important role for a comfortable thermal sensation, based on quality of movement, evaporative cooling (production of sweat) and metabolic rate. This paper investigates how people walking in a sequence of irregular spaces may experience thermal diversity through instantaneous variations with the potential for reducing thermal discomfort. Part of a wider longitudinal study, the aim of this paper is to present the differential thermal experience of urban microclimate as induced by a complex urban morphology in the spectrum of the temperate climate (warm and cold). Evaluating the thermal comfort conditions for pedestrians in movement, it provides an understanding of subtle changes in thermo-spatial conditions between interconnected spaces of a spatial sequence. The combined effect of urban morphology and materiality (Table 1) during walking provides a multivariable description of pedestrian thermal perception that contributes to the understanding of how to create more comfortable thermal experience for people in movement and to inform the principles of multisensory and healthier urbanism.

\section{The methodology of thermal walks}

The assessment of the way walkers perceive thermal variations in urban spaces due to their physical activity relies on a multiparametric analysis (Johansson et al. 2014). The interaction between embodied experience and the thermo-spatial environment mediated by walking forms the basis of this work. Two walking paths in temperate European sites were chosen, both placed in the historic core of London, UK, and Rome, Italy, representing popular everyday walking routes (Fig. 1). This selection resulted in comparing interconnected spaces with similar sequential geometric variations, at the scale of the neighbourhood, in the wider context of temperate climate. The period of on-site primary data collection took place in summer 2012 and winter 2013 in both cities to evaluate variations between seasons. Each case study comprised of a triptych of urban squares that are connected with short segments of streets, with a comparable differentiation in their geometric descriptors (aspect ratio and sky view factor). The London site starts at Seven Dials junction up to Covent Garden square, passing through Neal and James Street. The area is commercial with shops at the ground floor and offices on upper floor, with scarce vegetation. Most frequent uses of space include people meeting and pedestrian activities, with Covent Garden being the main place attractor. The selected site is the longest continuous semi-pedestrian route in the historic core of London. The equivalent route in Rome begins at Campo dei Fiori, an open-air market place at daytime, to conclude in Piazza Cairoli, one of the few urban squares with vegetation in the historic centre. Via dei Giubbonari connects the beginning and end of the route and is a sixteenth century commercial street of Rome, with unwavering use. The selected route is intersected in the middle by a small public space that is entirely enclosed, Largo dei Librari. Pedestrian activities take place. The route is densely built with compact blocks of buildings and narrow street segments. 
Table 1 Geometric descriptors at the scale of focus points for each of the thermal walks in Rome and London

\begin{tabular}{|c|c|c|c|c|c|c|}
\hline \multicolumn{2}{|c|}{ Focus points of monitoring } & \multicolumn{5}{|c|}{ Indicators at 'focus point' scale } \\
\hline & & Aspect ratio $\mathrm{H} / \mathrm{W}$ & Sky view factor & Average albedo of surfaces & $\operatorname{DoE}(0-1)$ & $\begin{array}{l}\text { DoE } \\
\text { (Steemers, 2004) }\end{array}$ \\
\hline \multirow[t]{6}{*}{ Rome } & $A_{R}$ & 0.45 & 0.54 & 0.2 & 0.2 & 4.85 \\
\hline & $\mathrm{B}_{\mathrm{R}}$ & 5 & 0.19 & 0.2 & 0.08 & 11.71 \\
\hline & $\mathrm{C}_{\mathrm{R}}$ & 0.44 & 0.42 & 0.2 & 0.16 & 5.95 \\
\hline & $\mathrm{D}_{\mathrm{R}}$ & 3.5 & 0.28 & 0.2 & 0.19 & 5.23 \\
\hline & $\mathrm{E}_{\mathrm{R}}$ & 1.2 & 0.47 & 0.2 & 0.22 & 4.57 \\
\hline & $\mathrm{F}_{\mathrm{R}}$ & $0.3(0.5)$ & 0.61 (vegetation incl.) & 0.27 & 0.38 & 2.65 \\
\hline \multirow[t]{6}{*}{ London } & $\mathrm{A}_{\mathrm{L}}$ & 0.76 & 0.57 & 0.2 & 0.74 & 1.35 \\
\hline & $\mathrm{B}_{\mathrm{L}}$ & 2.4 & 0.4 & 0.19 & 0.09 & 10.75 \\
\hline & $\mathrm{C}_{\mathrm{L}}$ & 1.25 & 0.49 & 0.2 & 0.54 & 1.85 \\
\hline & $\mathrm{D}_{\mathrm{L}}$ & 2.9 & 0.23 & 0.21 & 0.11 & 8.94 \\
\hline & $\mathrm{E}_{\mathrm{L}}$ & 1.7 & 0.32 (vegetation) & 0.2 & 0.17 & 5.77 \\
\hline & $\mathrm{F}_{\mathrm{L}}$ & 0.3 & 0.52 & 0.2 & 0.26 & 3.8 \\
\hline
\end{tabular}

\section{Microclimatic monitoring}

During the thermal walks, environmental monitoring took place simultaneously with group surveys, to evaluate objective data at street level with subjective perceptions. A portable weather station was fixed on an aluminium trolley with a CR800 Campbell Scientific datalogger and five sensors (complying with ISO 7726 1998) fixed on a telescopic pole at a height of $1.75 \mathrm{~m}$, to represent the average height of a pedestrian. The environmental monitoring included Tair and RH (using a CS215 probe with white radiation shield), Tglobe (CT100 probe), wind velocity (ultra-sonic two-dimensional anemometer) and illuminance (Skye lux meter). People completed a questionnaire during the simultaneous environmental monitoring. Participants recorded their subjective thermal sensation at each focus point. An infra-red thermometer gun was used to record surface temperatures of urban walls and pavement close to where participants were positioned. Precise time-monitoring, constant during the days of monitoring, was accompanied by photographic documentation, showing the participants' position next to the environmental equipment, and their position in the sun, shade and space in the street.

\section{Walking surveys}

Participants were part of a thermal walking group, repeating the walk at noon and at $2 \mathrm{pm}$. They were instructed to use their own personal pace and stop at six focus points in order to record their thermal sensation. The measuring device-a moving feature in itself - did not interfere with the walking pace of the participants. They were asked to evaluate their reaction to the thermal environment when they would stop in a square or in the middle of a pedestrian street, based on
Fig. 1 The routes of thermal walks in Rome (left) and London (right) (source: Google Earth 2013 adapted by author)
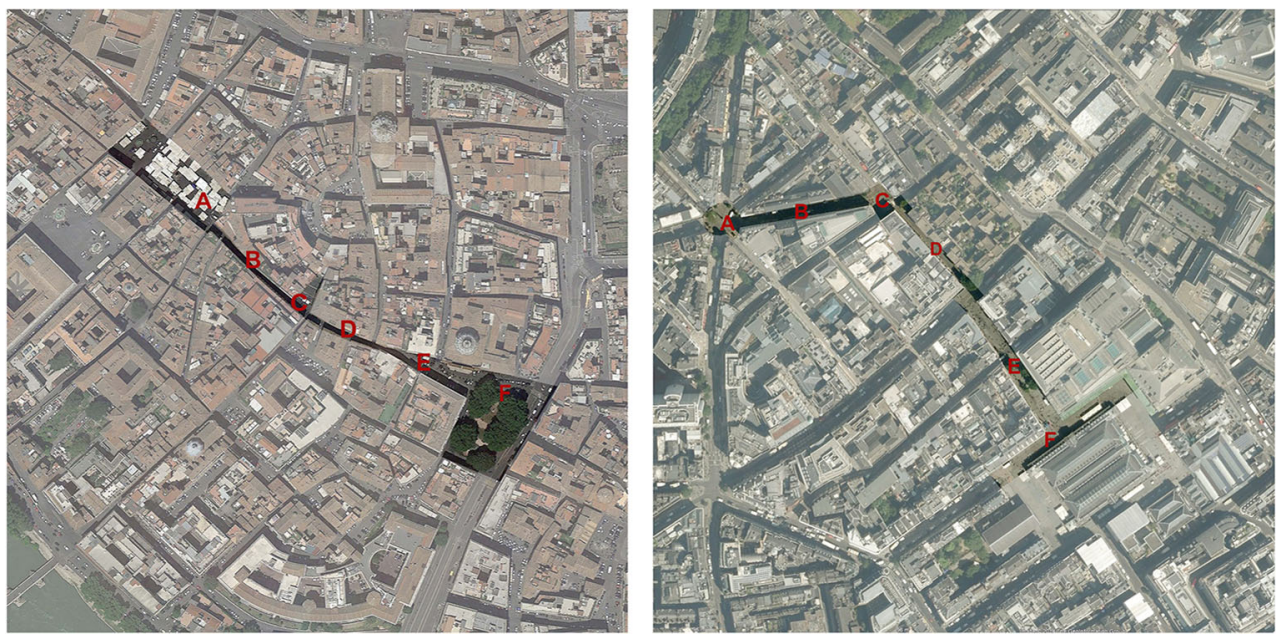
the questionnaire. Participants assessed their thermal sensation and its variation as they moved through the spatial sequence from one point to the other. The questionnaire was designed with a benchmark of actual sensation vote recorded for every focus point of the walk. This facilitates the comparative analyses of ASVs between walking points, but also the recording of the perceived differential ASV (dASV, i.e. the variation in thermal sensation between two interconnected urban spaces). The thermal walks questionnaire was developed including the evaluation of various aspects of thermal perception: thermal sensation, wind sensation, sunlight sensation, perceived thermal comfort and differential thermal sensation (dASV), shown in Table 2.

Participants were randomly selected. The groups of participants consisted mainly of people working in the street, researchers and general inhabitants of the city, who were shortly briefed about the nature of the research before the walk. An open-ended question on the quality of space allowed for any biased appreciations of the walks. They were studied in a natural situation that would inherently involve walking, to evaluate their perception of the thermal and spatial environment. The survey was completely structured and prearranged with people from a wide range of background that had given consent of participation beforehand. In the structured questionnaire, the participants were asked to concentrate on the variations that might occur between different points of the walk, in terms of their thermal sensation, preferences and characteristics of the space around them.

Overall 314 thermal walks questionnaires were completed in London and Rome. Participants walked and evaluated their thermal sensation, state of comfort and the surrounding space at six different points along the given route, completing the relevant questionnaire section with both close- and open-ended questions. The walks were repeated daily during the monitoring periods at $12 \mathrm{pm}$ and $2 \mathrm{pm}$, to evaluate the differences in the thermal environment resulting from the effect of the solar angles and the sun and shade patterns in the space at different times of the day. There were 5 to 10 participants per day, repeating both walks. The initial part of the questionnaire included completing general data about gender, age range, clothing level to indicate clothing insulation and, finally, food and/or drink consumption. General data concerning the time span of the walk was completed by the researcher at the time of questionnaire collection. Due to the nature of the research that uses sense-walking techniques, the engagement of participants on a long-term basis (repeating the same walk twice in the same day) and the duration of every survey $(30-40 \mathrm{~min})$, the recruitment of participants was challenging.

The study is based on a longitudinal approach with some participants engaging in a dynamic assessment of their thermal perception (Table 3). Completed questionnaires are usually twice the number of participants, as $90 \%$ of those participated in both walks of the day of fieldwork. The age range is fairly well represented with one peak at the category of 25-34. Clothing levels for summer and winter conditions vary between $0.30-0.70$ and $1.00-1.65$ respectively which are considered appropriate for each season.

\section{The microclimate of two spatial sequences}

A series of graphs (and DEMs) show the combination of multiparametric data that depict the variations in microclimatic conditions (graphs (c) and (d)) and actual sensation votes (graphs (a) and (b)) during the thermal walks. Figure 2 focuses on the thermal walks in Rome during summer 2012 for every minute of the walk from point $\mathrm{A}$ to point $\mathrm{F}$ at 12 noon and $2 \mathrm{pm}$. At 12 noon the most thermally pleasant variation (approx. 60\% of participants) occurred in spaces $\mathrm{D}(\mathrm{H} / \mathrm{W}=6$,

Table 2 The questionnaire was designed to record changes in the thermal sensation of pedestrians during their movement (in a 5-point scale: colder, cooler, none, warmer, hotter) and perceived comfort condition

Question 1 (ASV)

How do you find the thermal environment at this precise moment?

Temperature
a) Cold
b) $\mathrm{Cool}$
c) Neither warm nor cool
d) Warm
e) Hot
Wind
a) No wind
b) Breeze
c) $\mathrm{OK}$
d) Windy
e) Too windy

Sun
a) Would like more
b) $\mathrm{OK}$
c) too much sun

Question 2 (dASV)

Do you feel a thermal variation in relation to your previous sensation?
a) Colder
b) Cooler
c) No variation
d) Warmer
e) Hotter

Question 3 (PTC)

You find this:

a) Uncomfortably cold

b) Uncomfortably cool

c) Comfortable

d) Uncomfortably warm

e) Uncomfortably hot 
Table 3 Participants' descriptive sample for winter and summer walks in Rome and London respectively

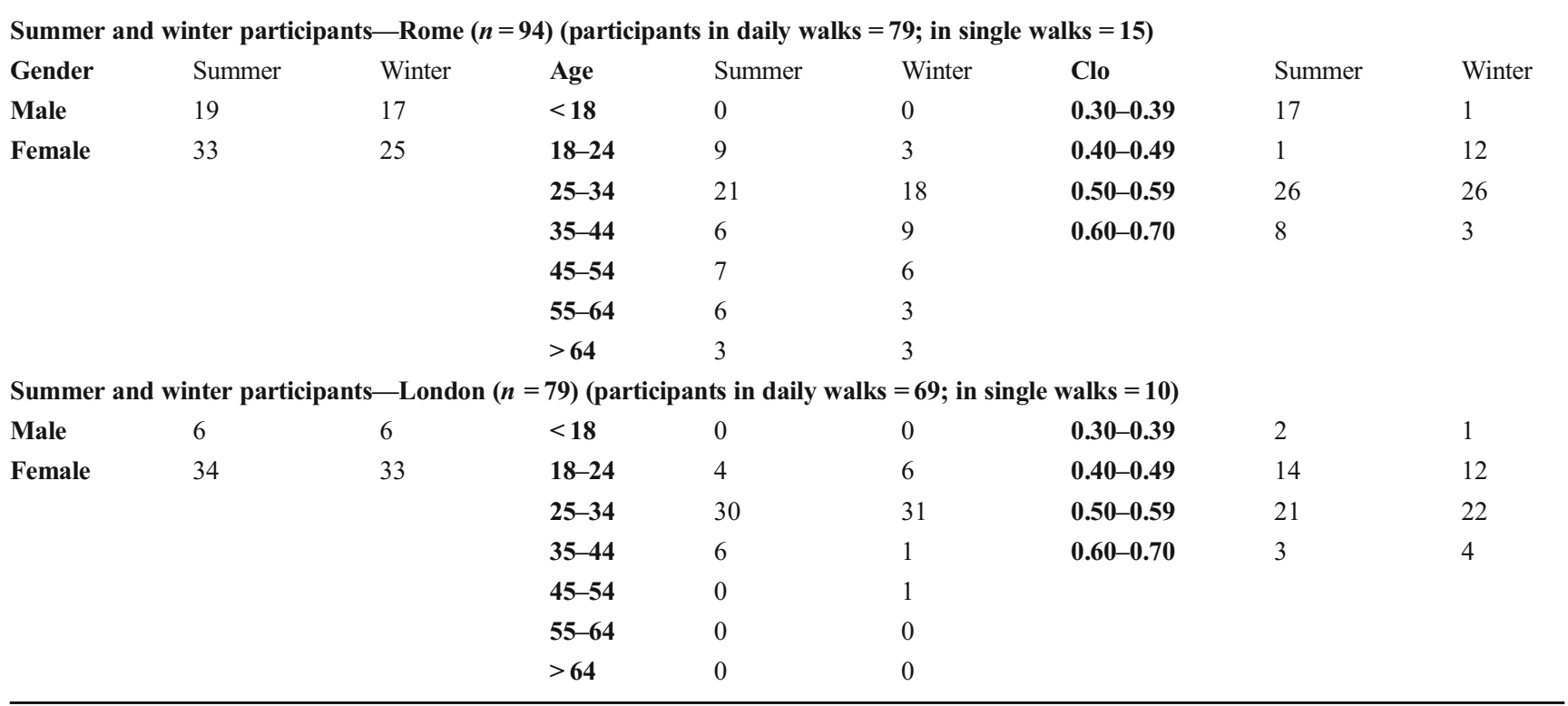

$\mathrm{SVF}=0.18)$ and $\mathrm{F}(\mathrm{H} / \mathrm{W}=0.4, \mathrm{SVF}=0.36)$. At $2 \mathrm{pm}$, more than $60 \%$ of the same participants recorded space $\mathrm{B}(\mathrm{H} / \mathrm{W}=8$, $\mathrm{SVF}=0.11$ ) as the space with the thermally pleasant variation.

As expected, air temperature and relative humidity remain homogeneous throughout the walks. Wind velocity and solar radiation/light intensity influence largely the variation in ASV of participants between points. The collected data is coupled by two maps ( $\mathrm{i}$ and ii) that show the position of people during monitoring. The digital elevation models show that at 12 noon $40 \%$ of participants were positioned in the sun (even in spaces with $\mathrm{H} / \mathrm{W}>2.5$ ), while at $2 \mathrm{pm} 93 \%$ of participants walk in shade. The occurrence of clear or overcast sky during the walk is shown by the blackand-white bank in the middle of the matrix in Fig. 2.

Similar analysis is shown for walks in Rome during winter. Figure 3 shows the Largo dei Librari $(\mathrm{C})(\mathrm{H} / \mathrm{W}=0.9, \mathrm{SVF}=$ 0.35 ) as one of the most thermally pleasant for both 12 noon and 2 pm walks. In colder conditions, the number of participants (max. of $50 \%$ ) that vote no variation in their thermal sensation throughout the walk is increased (in comparison with a max. of $25 \%$ during warm seasonal conditions). The positioning of participants becomes non-relevant for winter conditions, as overcast sky prevailed during the days of monitoring. In clear sky conditions, the sun penetration would not reach street level and thus, sun/shade patterns were not taken into consideration in terms of where the participants positioned themselves.

In the London case study (Fig. 4), summer variation in ASV is non-homogeneous (that means that votes are divided between cooler and warmer throughout walk), applying to both daily walks. Neil square, located at a crossroad $(\mathrm{H} / \mathrm{W}=$ $1.1, \mathrm{SVF}=0.41)$, received the votes for the highest change in a thermally pleasant sensation $(72 \%$ of participant voted a warmer thermal sensation at $2 \mathrm{pm}$ walk). Wind velocity and solar radiation conditions were the main influence for this perceptual variation. Transitions from higher to lower aspect ratios (2.6 to 1.1$)$ at 2 pm were voted as thermally more pleasant, warmer, during fairly overcast conditions and with wind velocity decreasing from 1.5 to $0.8 \mathrm{~m} / \mathrm{s}$. In winter conditions (Fig. 5) at $12 \mathrm{pm}$, Tair remains stable throughout the walk at $5{ }^{\circ} \mathrm{C}$, while mean MRT remains below Tair values from points $\mathrm{A}$ and $\mathrm{B}$, while gradually increasing from point $\mathrm{C}$ until the end of the walk. Points $\mathrm{E}$ and $\mathrm{F}$ present the highest means of MRT at $6{ }^{\circ} \mathrm{C}$ and $8{ }^{\circ} \mathrm{C}$ respectively. A slight variation between points occurs at the transition from point $\mathrm{A}$ to point $\mathrm{B}$, with an average $\triangle \mathrm{MRT}$ of $2 \%$. Average wind speed shows fluctuation during the walk with minimum value of $0.5 \mathrm{~m} / \mathrm{s}$ and maximum wind speed of $2 \mathrm{~m} / \mathrm{s}$ occurring at point $\mathrm{D}$. The small range of values reflects the overcast conditions prevailing during the winter session of thermal walks. Average wind speed at 2 pm shows slight fluctuation during the walk, with maximum value of $2.1 \mathrm{~m} / \mathrm{s}$ occurring at point $\mathrm{D}$ and minimum values of approx. $0.5 \mathrm{~m} / \mathrm{s}$ at point $\mathrm{F}$. There is slight variation of $0.5 \mathrm{~m} / \mathrm{s}$ during the transitions from points $\mathrm{C}$ to $\mathrm{D}$ (increase) and from points D to E (decrease).

\section{Perceived thermal sensation during walking}

The two routes in Rome and London are characterised by a similar variation in aspect ratio and sky view factor. However, the effect of microclimatic differences is evident on people's perceived thermal comfort while walking. In winter, while pedestrians in Rome found a comfortable thermal state during their walk, in London the perception was predominantly uncomfortably cool for the duration of the walk. The effect is 
a

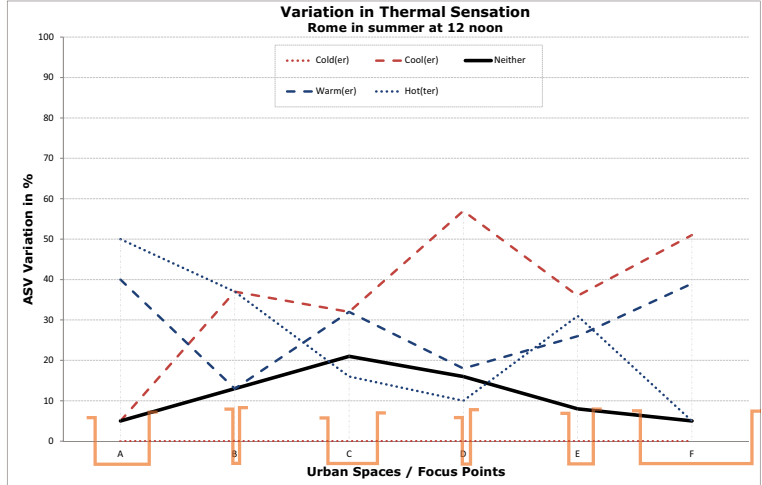

b

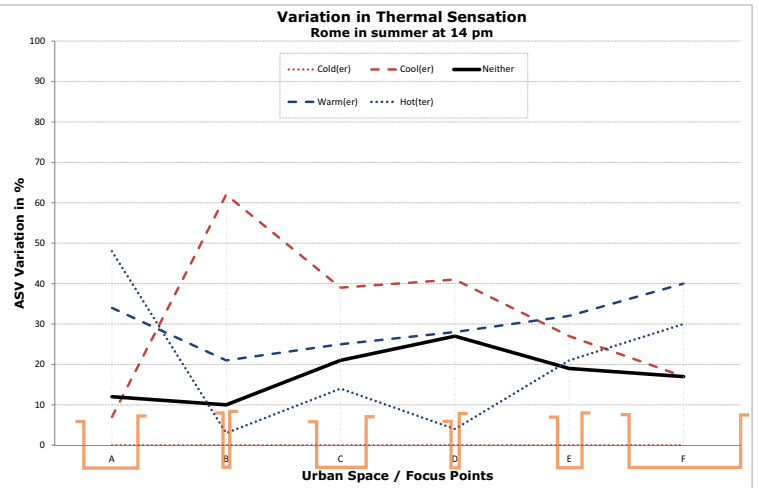

C

Environmental diversity / Rome / summer

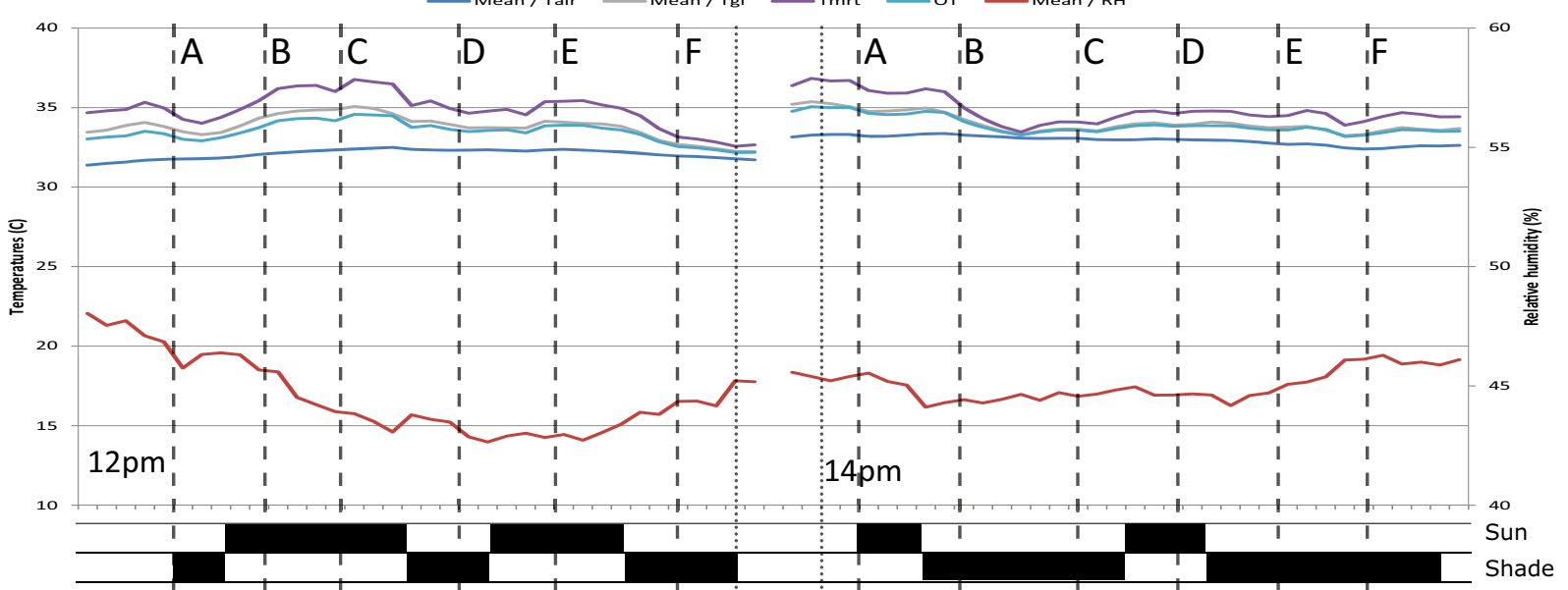

d

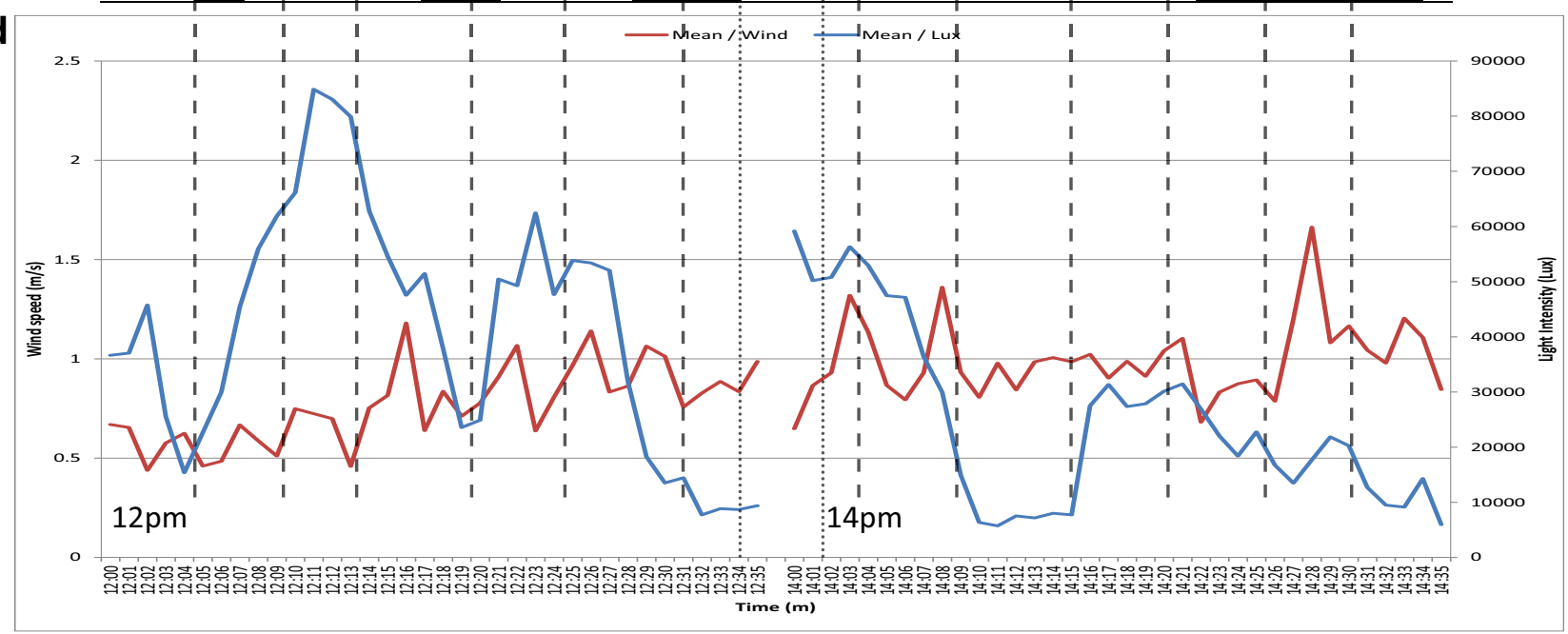

\section{i}

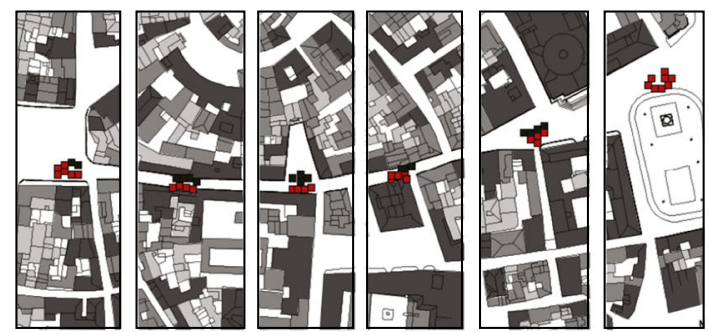

Fig. 2 Diagram of the factors connecting ASV, actual climatic data and geometric descriptors of the summer thermal walks in Rome. Graphs (a) and (b) show the variation in the ASV and H/W ratios; graphs (c) and (d)

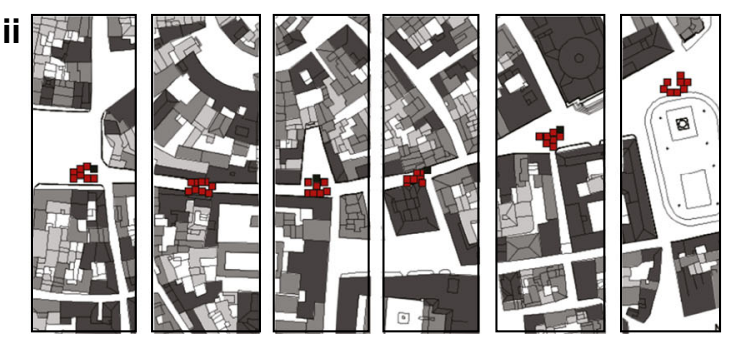

show the Tair, MRT, RH, wind speed and light intensity data; and maps $\mathrm{i}$ and ii show the DEMs with positioning of participants 

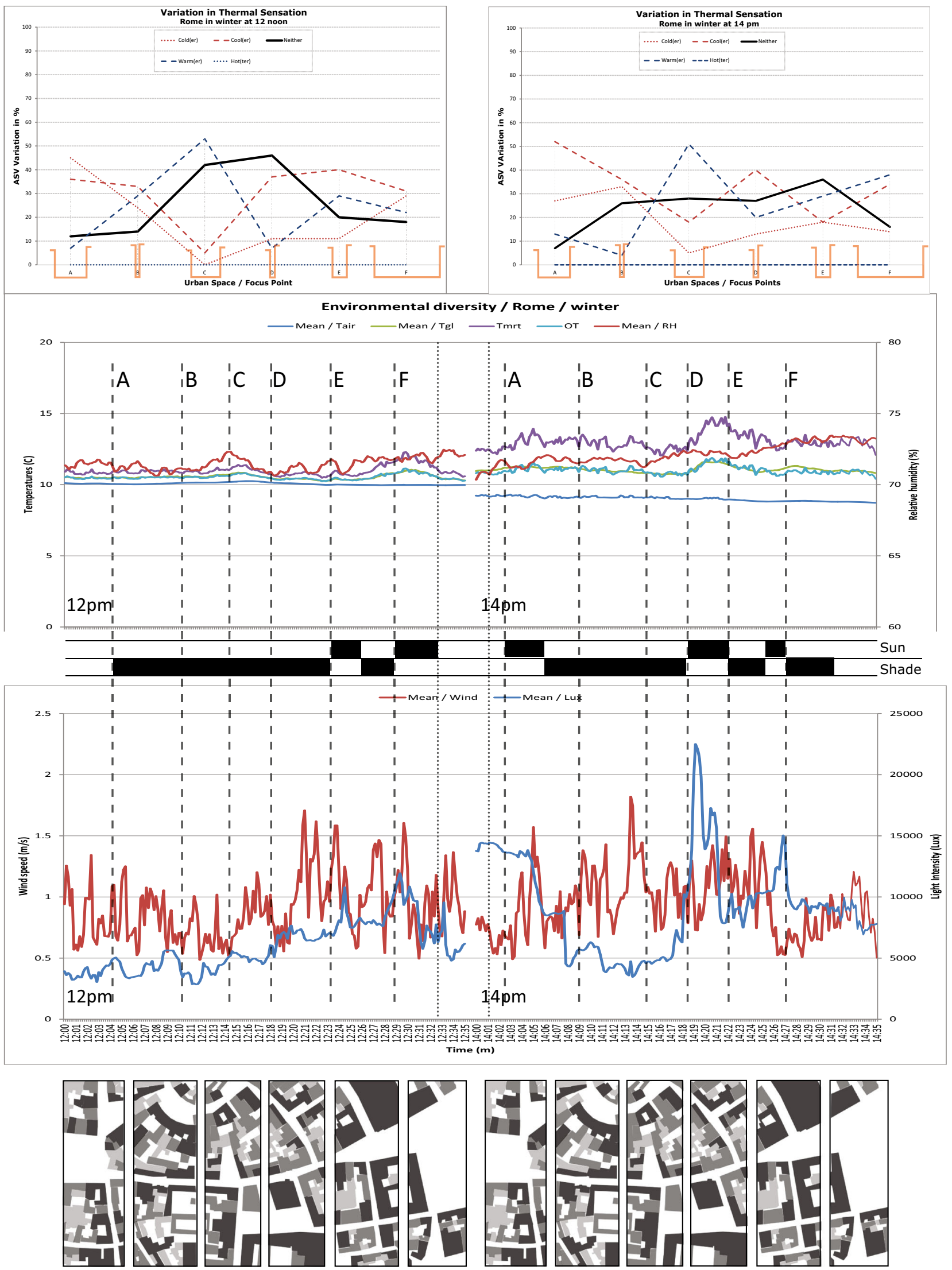

Fig. 3 Similar use of diagrammatic visualisation of data for the ASV variation (dASV) in winter Rome at 12 noon and how it is connected to the H/W ratio of each focus point of the walk 

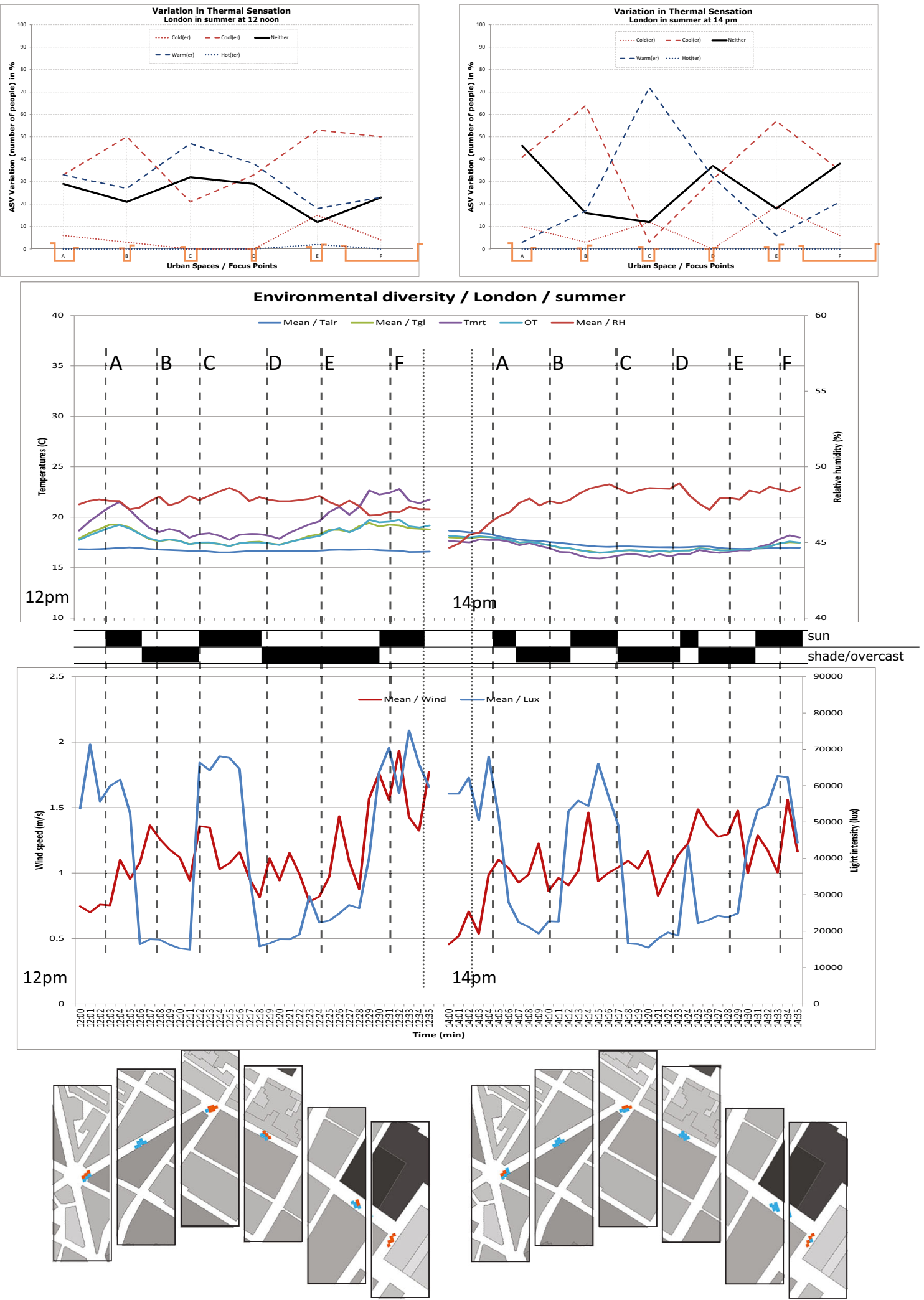

Fig. 4 The data collection of ASV, actual climatic data and geometric descriptors for London during summer

reversed for summer conditions: people's perception in Rome is divided between a comfortable and uncomfortably warm state, whereas in London people voted for a consistently comfortable thermal experience throughout the walk. 

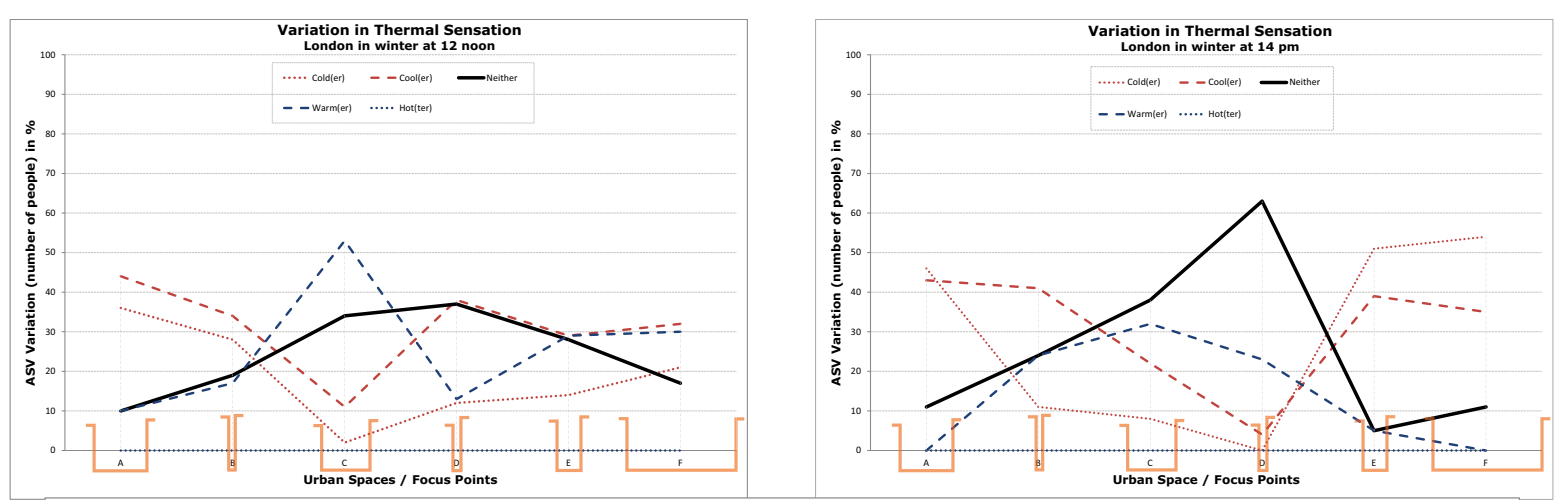

Environmental diversity / London / Winter
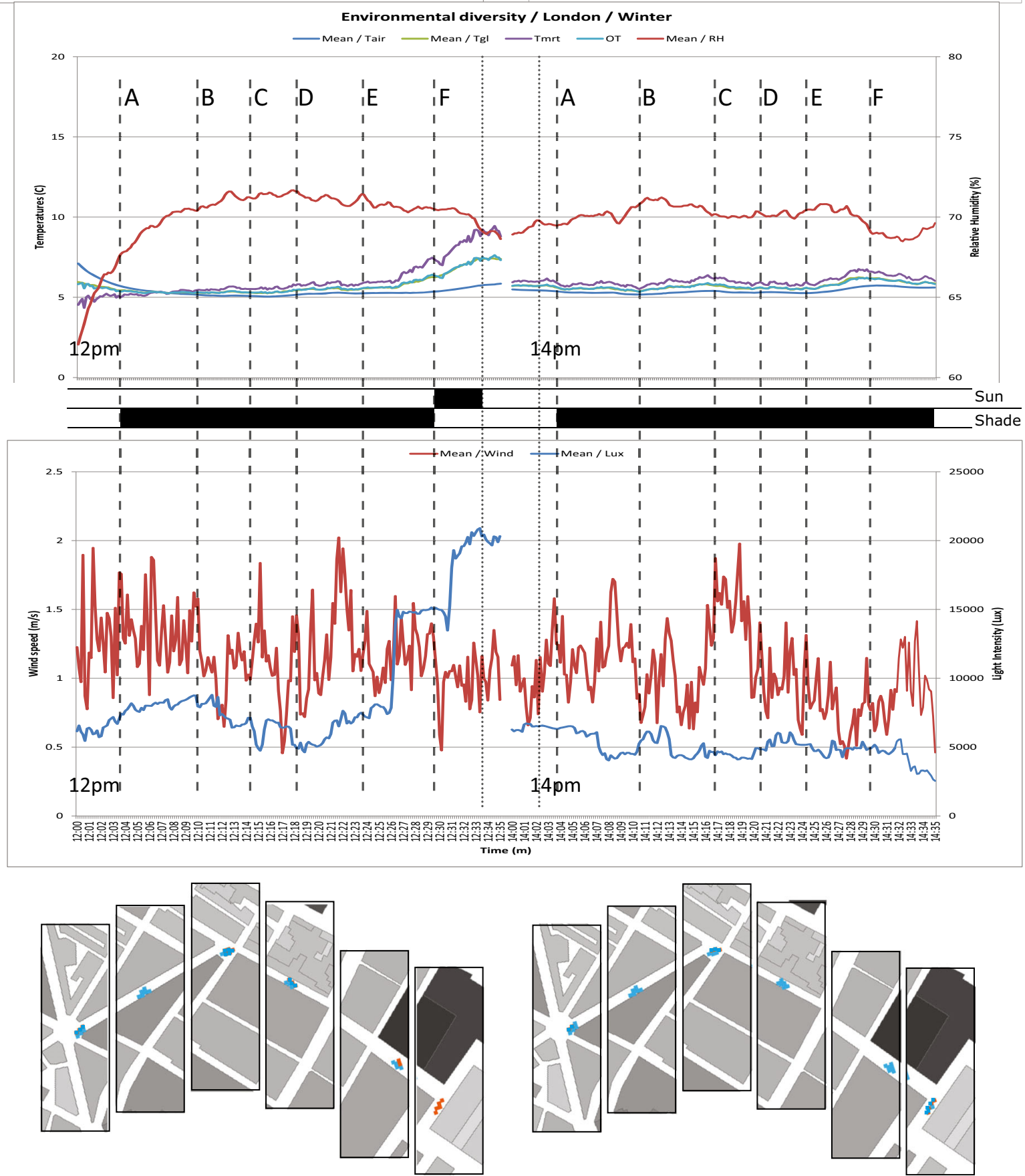

Fig. 5 The multivariable diagram for London thermal walks during winter conditions 
Fig. 6 Perceived thermal comfort (PTC) and aspect ratio $(\mathrm{H} / \mathrm{W})$ of the six focus points (A, B, C, D, E and $\mathrm{F}$ ) in Rome and London during winter
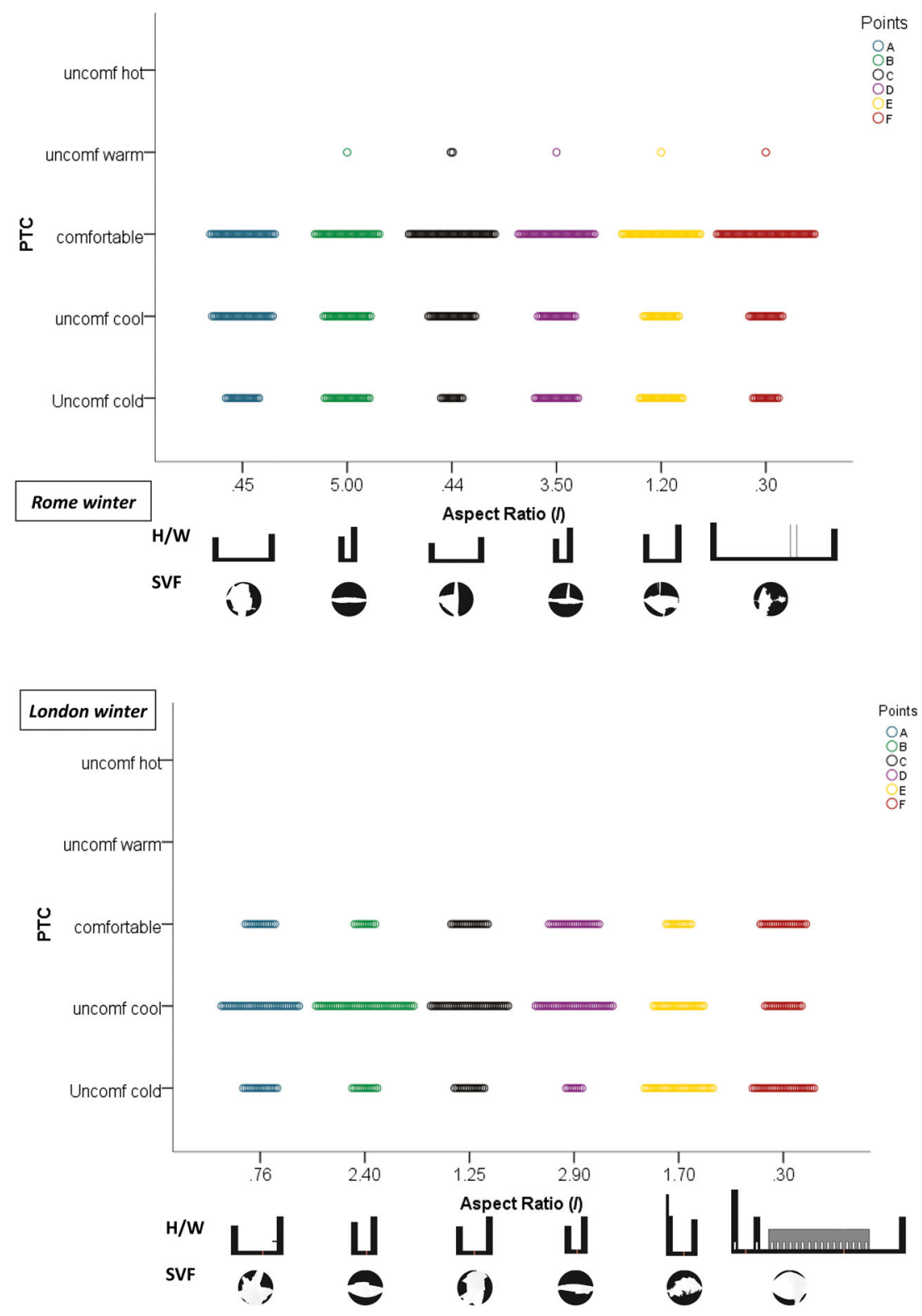

Looking at the variation of the thermal experience between spaces along the walk of Figs. 6 and 7, there are subtle variations in the relation between perceived thermal comfort (PTC) and the aspect ratio (H/W) of the six focus points (A, B, C, D, E and F) in Rome and London. For example, in London, during winter conditions, there is no distinct tendency between PTC and aspect ratio (Figs. 6 and 7). However, despite the spatial homogeneity of the urban fabric (low variation in aspect ratio between spaces), people's responses show a higher variation in perceived thermal comfort between spaces than in Rome for the same season (without a pattern emerging that differentiates squares and streets). Two groups are created: points A, B, $\mathrm{C}$ and D (uncomfortably cool) and points $\mathrm{E}$ and $\mathrm{F}$ (uncomfortably cold). For Rome in winter, there are two groups of sensations: in points $\mathrm{C}$ and $\mathrm{F}$ people responses show a comfortable thermal experience, while points A, B, $\mathrm{D}$ and $\mathrm{E}$ show a slightly uncomfortable experience. Summer conditions show reversed patterns for the two cities. In Rome, a thermally comfortable experience is achieved in spaces with higher aspect ratios (narrow streets), whereas uncomfortably warm experiences are reduced when moving towards the end of the route to a square with vegetation and presence of a water fountain (element of 'naturalness'). It is suggested that the beginning of the walk, points $\mathrm{A}-\mathrm{C}$, forms one thermal experience, followed by points D-F (more comfortable), due to both the effect of urban morphology and the expectation of being in a space 
Fig. 7 Summer variation in PTC between focus points of the thermal walk
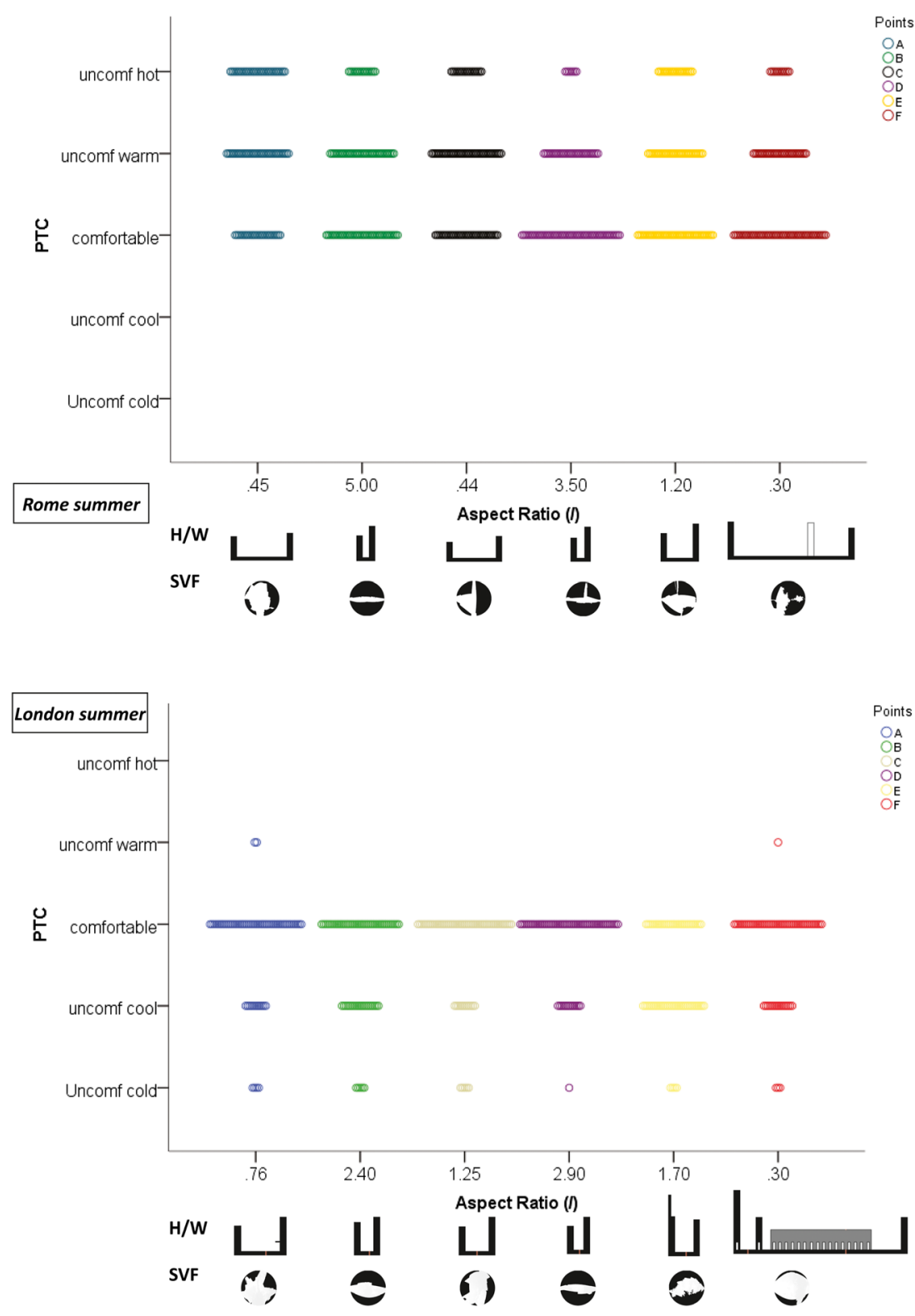

with vegetation and natural shading. In London, the perceived thermal comfort state is fairly even throughout the perception of thermal comfort, mainly due to the lack of
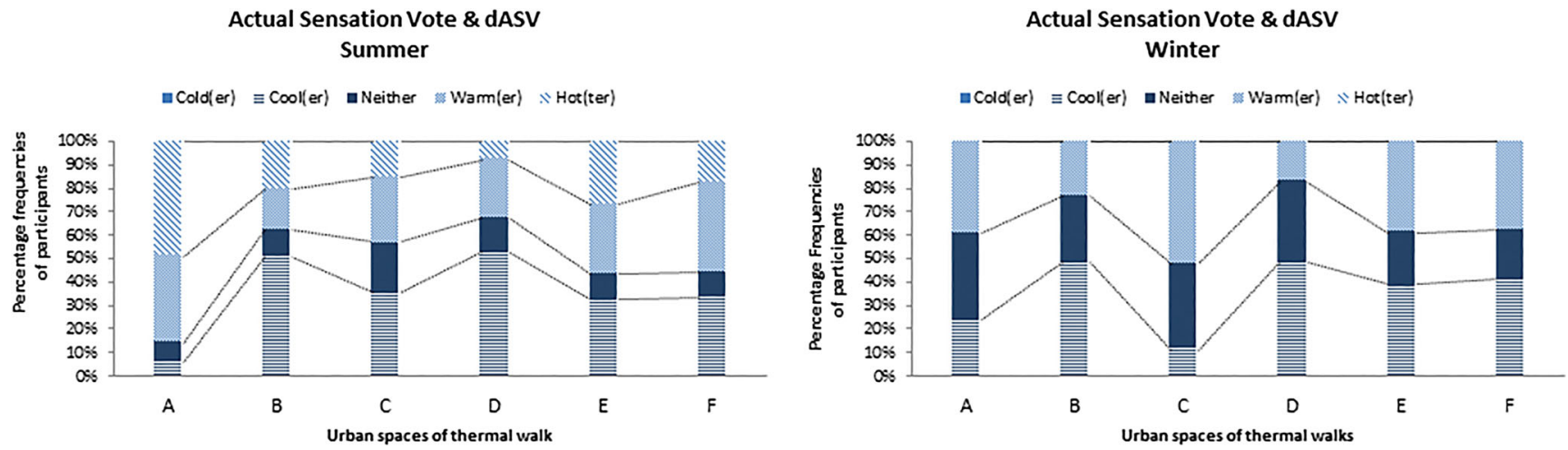

Fig. 8 Actual sensation votes (ASV), dASV in Rome during summer and winter 

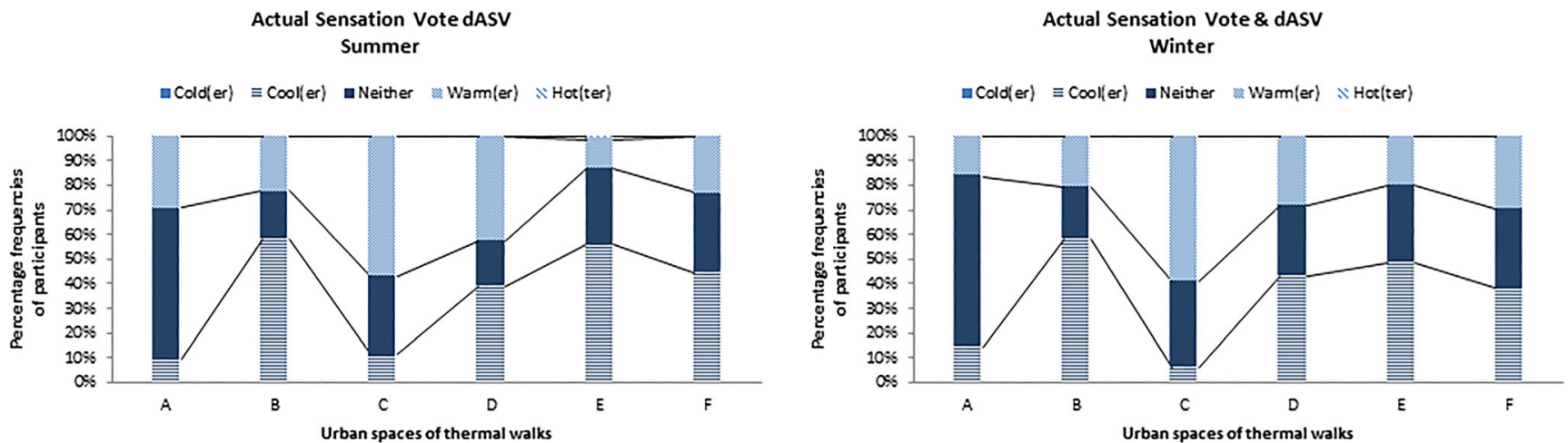

Fig. 9 Summer and winter variation in ASV between focus points of the thermal walk in London

exposure to direct solar radiation and the orientation of the street axis in parallel to the prevailing wind direction.

\section{Variation in actual sensation votes in London and Rome}

Actual sensation vote (ASV) and its variation (dASV that records colder, cooler, no variation, warmer or hotter effects) across the length of the route show a noticeable change in the thermal perception between the six focus points. Although in both cities neutral ASV and dASV remain similarly low (Figs. 8 and 9), specific spaces along the route result in changes in the prevailing thermal perception. For example, during winter in Rome, the small, enclosed square in the middle of the walk (point $\mathrm{C}$ ) causes a warmer thermal sensation for the majority of participants. This is reversed when people continue their walk in the shaded and narrow street canyon. In London, the reverse pattern seems to occur. People record a warmer thermal sensation when they move from an exposed small square (point $C$ ) to the narrowest part of the selected path (point D). This shows that irregularity in the urban fabric can account for instances of thermal pleasantness along a route.

\section{Rome}

Figure 8 presents the frequencies of the actual sensation votes of participants for points $\mathrm{A}$ and $\mathrm{F}$, along with the changes in their thermal perception (dASV) for points B, C, D and E during summer for both the $12 \mathrm{pm}$ and $2 \mathrm{pm}$ walks. During summer walks, the majority of participants started the walk with a thermal sensation of 'warm' (38\%) or 'hot' $(49 \%)$. During the walk and the transition from squares to streets and vice versa, $40-55 \%$ of participants felt 'warmer' or 'hotter' and $35-50 \%$ of participants felt 'cooler' while moving from spaces B, C, D and E. The walk ended with $40 \%$ participants feeling 'warm', 15\% participants feeling 'hot' and 35\% of participants feeling 'cool'. Throughout the walk, at spaces B, C, D and E, only $10-20 \%$ of participants did not perceive any thermal variation. In total, no participant voted for a 'cold' or 'colder' sensation.

During winter conditions, participants voted the starting point of Campo dei Fiori as 'warm' (40\%), 'cool' (22\%) and 'neither cool nor warm' (38\%). Participants finished the walk with a 'warm' thermal sensation (40\%), a 'cool' thermal sensation (40\%) and 'neither' at 20\%. During the physical transition along Via dei Giubbonari from point B to point E, the thermal sensation of participants varied so that $25-50 \%$ felt warmer, $10-50 \%$ felt cooler and $20-40 \%$ felt no thermal variation. Interestingly, votes of 'cold(er)' thermal sensation were not recorded by participants. This may be explained by the wide range of daily air temperature during the fieldwork, which ranged from 5 to $15^{\circ} \mathrm{C}$.

In addition, according to Fig. 8, there is pattern in the ASV and dASV votes in winter conditions. Participants seemed to vote for warm and warmer thermal sensations in spaces with the morphological characteristics of a square (points A, C, E and $\mathrm{F}$ ) with votes ranging from 40 to $50 \%$. This is consistent with increased ASV and AASV votes of cool and cooler thermal sensations in narrow urban canyons, such as points B and D. However, variations in microclimatic conditions from point to point (as shown in Figs. 2 and 3) are significantly low. While Tair and $\mathrm{RH}$ show no significant variation from point to point $\left(\Delta\right.$ Tair $=0.15{ }^{\circ} \mathrm{C}$ and $\left.\Delta \mathrm{RH}=2 \%\right)$, MRT shows a variation of $0.1{ }^{\circ} \mathrm{C}$, from point $\mathrm{A}$ to point $\mathrm{B}$ and a maximum $\triangle \mathrm{MRT}$ equal to $0.6^{\circ} \mathrm{C}$, when moving from point $\mathrm{D}$ to point $\mathrm{E}$. The same pattern may be observed for wind speed, although the variation is significantly low $(\Delta \mathrm{WS}=0.1 \mathrm{~m} / \mathrm{s})$.

These relations between subjective responses and monitored data may suggest that the participants' thermal perception is highly responsive to slight fluctuations in the microclimatic conditions. At the same time, this relation could be further investigated in terms of the morphological characteristics of the spatial sequence.

\section{London}

Figure 9 shows the differentiation of thermal perception (ASV and $\mathrm{dASV}$ ) during the transition from one focus point to the 
next one for summer and winter respectively for both $12 \mathrm{pm}$ and 2 pm walks. A high number of participants perceived the thermal environment to be 'neither cool nor warm' $(60 \%)$ at the starting point A of the thermal walk in summer. This tendency for higher 'neutral' votes may be observed throughout the walk. In the spatial sequence, thermal perception varies significantly from one point to the other. Neutral votes show an alternation of increased and decreased frequencies during the walk. At point B, 19\% of participants voted for 'no variation'. At the same time, $59 \%$ of participants voted that the transition from point A (square) to point B (street) resulted in a cooler thermal sensation. This vote was reversed for point $\mathrm{C}$, where $32 \%$ of those questioned did not sense any thermal variation and $58 \%$ found this transition warmer. Interestingly, at point D (narrow street), participants' votes were divided between a cooler and a warmer thermal sensation (39\% and $42 \%$ respectively), while 'no variation' vote was reduced to $18 \%$. At points $\mathrm{E}$ and $\mathrm{F}, 30 \%$ of participants sensed 'no thermal variation' and 'neither cool nor warm' respectively during the transition. At the same time, the movement from one space to another resulted in no significant variation in the 'cool(er)' vote (48\% and $38 \%$ respectively). Interestingly, the extreme votes (cold(er) and hot(ter)) were not selected by participants, except for a small minority of $2 \%$ who voted a hotter thermal sensation at point E. In terms of variation, summer data show that narrow streets $(\mathrm{H} / \mathrm{W}>2)$ may be linked to high frequencies of cooler thermal perception by those surveyed than squares in the given route. However, for an urban canyon of $\mathrm{H} / \mathrm{W}>3$ that may provide at the same time both sunlit and shaded zones, participants seem to be equally divided between a cooler and warmer sensation. Finally, streets that possess the geometric characteristic of an oblong square (such as point E) and oblong squares (point F) seem to produce a similar thermal sensation effect as that of a narrower street, with high frequencies of a 'cool(er)' thermal sensation. That is in contrast with the prevailing thermal sensation and variation of centralised spaces (warm(er)), such as the square in point $\mathrm{C}$. In terms of no variation, narrow streets, such as points B and D, share a low frequency of votes (18\%) by those questioned. This is in contrast to increased frequencies at point $\mathrm{C}$ (square) and point $\mathrm{E}$ (wide street) where $32 \%$ found no variation in their movement from a narrow street to a square or wide street.

During winter conditions, unaltered thermal sensation votes are shown for a seasonal change of Tair equal to $12{ }^{\circ} \mathrm{C}$. The exact pattern of variations is observed for each focus point. However, it is interesting to point out the higher frequencies of neutral votes ("neither cool nor warm' and 'no variation') throughout the walk than the one in summer fieldwork. This may suggest that cool climatic conditions in the winter period may flatten microclimatic variations or hinder their perceived variation by the participants. At the same time, an increased percentage of 'warmer' dASV for point C is consistent for both summer and winter microclimatic conditions. This might suggest that a variation in the thermal perception which improves thermal comfort (warmer is more pleasant sensation in the cold temperate climate) may be found in the middle of the walk at Neil Square (C).

From the opposite spectrum, Earlham street (point B) shows consistently in summer and winter an increased percentage of participants that perceive a 'cooler' thermal sensation when moving to this street. Poor insolation might explain this tendency. However, it shows an expected result: moving from an open space where thermal sensation is thermally neutral according to at least half of the participants to a narrow urban canyon which remains in shade for the larger part of the day seems to produce a sense of thermally cooler feeling. It is suggested that this may be due to sun exposure, the presence of overhead protection and high vehicular traffic that contributes to anthropogenic heat production.

Finally, findings at point A confirm the significance of the architectural arrangement of the urban space. Neutral votes are voted at high frequencies for both summer and winter. Surprisingly, during the winter walks, $68 \%$ of those surveyed voted the thermal sensation as 'neither cool nor warm'. This may be attributed to the effect of walking activity prior to the commencement of the thermal walk, but most significantly to the presence of a canopy close to the positioning of the survey group.

The geometric descriptors of the six focus points (A, B, C, $\mathrm{D}, \mathrm{E}$ and $\mathrm{F}$ ) in Rome and London show subtle variations. It is interesting to point out the deviations from the standard patterns of ASV-dASV in relation to aspect ratio during winter in Rome, where the only outlier is point $\mathrm{C}$, which is attributed the majority of 'warm(er)' votes. In summer, points B and D (streets) provide the 'cool(er)' effect, whereas point $\mathrm{A}$ is attributed with the majority of the negative spectrum of ASV for the season. Similarly, in winter London (Fig. 9), point D provides the 'warm(er)' and 'neither_no variation' votes in contrast with the rest of the points. Finally, during summer in London, point $\mathrm{D}$ provides an equal spectrum of middle votes, whereas point $\mathrm{C}$ is attributed the 'warm(er)' ASV-dASV.

\section{Comparison between cities}

In order to understand the effect of urban morphology on the average perceived thermal comfort (PTC), statistical analysis is carried out, comparing average PTC variation in squares, such as points A, C and F, compared with streets, such as points $\mathrm{B}, \mathrm{D}$ and $\mathrm{E}$. Figure 10 shows the variation between cities and seasons for the different interconnected spaces of the thermal walks. During summer, the people walking in Rome reported less thermal discomfort in streets than in squares $(t(50)=-2.622, p=0.012$ and $\mathrm{Mstr}=1.38$ vs. $\mathrm{Msq}=1.22$ ). This may occur due to the increased shaded 


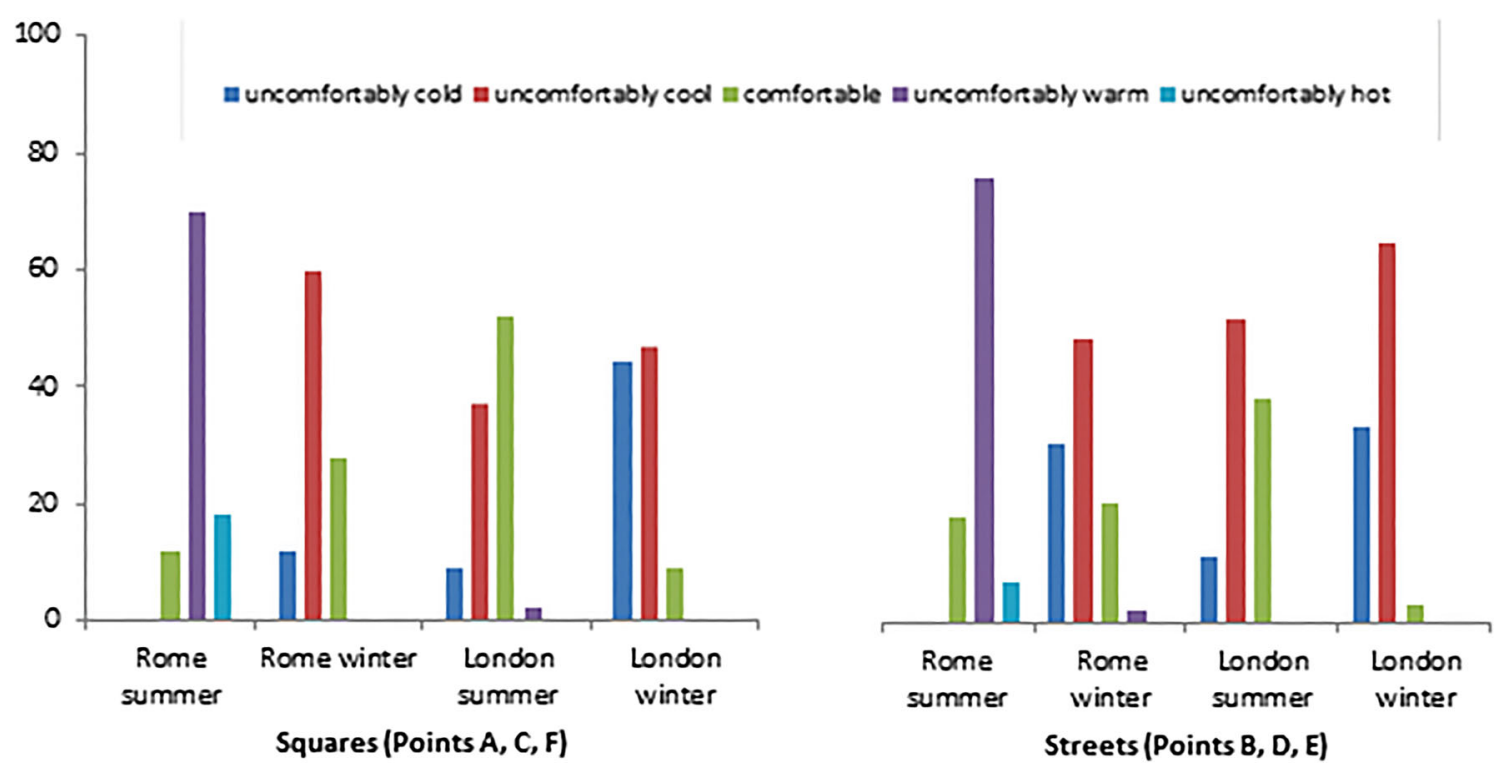

Fig. 10 Perceived thermal comfort between streets and squares in the two cities during summer and winter

parts of the street canyons and the effect of wind channelling. During winter time in Rome, squares were reported more thermally comfortable than streets $((t)(41)=2.508$, $p=0.016$ and $\mathrm{Msq}=1.34$ vs. Mstr $=1.18)$. This may occur due to the increased solar exposure in the squares of the route.

In London, the comparison between streets and squares shows marginal differences. Squares are perceived as more thermally comfortable in summer $(t(33)=1.981, p=0.056$ and $\mathrm{Msq}=1.67$ vs. Mstr =1.54). However, PTC for both urban entities, streets and squares show a relatively high degree of thermal comfort. This may occur due to low changes in the variation of aspect ratio between the interconnected spaces that resulted in low variation in the perception of thermal comfort. During winter no significant differences between streets and squares were recorded $(\mathrm{t}$ $(34)=-0.281, p=0.780)$. Participants found the walk uncomfortably cool throughout the overall route. This may occur due to the seasonal low temperature, as well as low solar radiation that resulted to a relatively homogeneous cold thermal sensation.

Conducting a one-way ANOVA $(F(3,158)=13.522$, $p=0.000$ ) for the four fieldworks in summer and winter showed variations between the two locations, London and Rome. Perceived thermal comfort did not show significant variation between summer and winter Rome $(p=$ 0.000 ). In London, average PTC during summer was higher the equivalent from Rome $(p=0.015)$, while average PTC in winter was lower $(p=0.007)$. This suggests that outdoor thermal comfort is achieved in Rome during both seasons due to the higher complexity of the urban morphology and higher opportunities of urban surfaces to be exposed in solar radiation. In London, only summer walks showed opportunities for thermal comfort while conditions in winter would require a mitigation strategy.

\section{Conclusion}

Observing dynamic thermal sensation in interconnected spaces can reveal significant understanding about the impact of intricate urban morphology on the microclimatic conditions and subsequent thermal perception of people in movement. The physical act of walking acted as a mediator in the juxtaposition of objective monitoring of the thermal environment and the collection of subjective people responses. The complexity of the study and its visualisation creates challenges to the urban designer. The thermal walks in the two cities during two different seasons (summer and winter) reveal the reverse thermo-perceptual effect for each set of participants, mainly due to differences in air temperature. Perceived thermal comfort was recorded for both locations, with the thermal walk in London during summer showing the higher rate of satisfied participants of all thermal walks. An evident differentiation between streets and squares was recorded in Rome for both seasons, with the diversity of spatial typologies providing the potential of thermal comfort according to the time of the year. This was not observed for the London case study, where winter fieldwork was not done under ideal conditions. In terms of morphological descriptors, aspect ratio and its variation in the spatial sequence play the foremost role in differentiating thermal comfort in squares and streets (particularly in Rome). In summer, streets seem to provide a higher potential of cooler conditions of thermal 
variation than squares. However, the resulting thermal sensation still lies in the comfortable-uncomfortably-warm spectrum. Variation exists but it is subtle. Conversely, squares in winter Rome provide a more thermally comfortable effect during the walk.

Using case studies from the historic core of metropolises provides the benefit of exploring unique urban spaces of continuous use in time. In these, the perception of thermal comfort by pedestrians seems to derive from the opposite function of adjacent spaces. It is not squares or streets that may be thermally comfortable. It is the variation created by the adjacency of a street to an open space that may provide a thermally interesting transition in the urban continuum.

Combining dynamic thermal experience and urban morphology revealed the need for more detailed quantitative and qualitative description of urban entities in order to identify all spatial characteristics that may result in a specific thermal sensation according to time of day and season. At the scale of the spatial sequence, an intermediate scale between the urban entity and the neighbourhood, the degree of complexity seems to determine the thermal diversity of the urban continuum. The research has demonstrated that the use of thermal walks can provide an in-depth knowledge of the role of irregular urban forms in contributing to thermal diversity at street level. Findings suggest a greater thermal diversity was found in the urban texture of Rome, rather than in London. This understanding opens possibilities in developing a multisensorycentred urbanism, where the experience of the thermal environment plays an integral role for perception-driven design.

Acknowledgements The author would like to thank Simos Yannas from the Architectural Association for hosting the portable weather station during the London fieldwork and the informative discussions; Marina Baldi, Ibimet Rome, Carmen Maria Beltrano, Ibimet Rome and Anna Maria Siani, University La Sapienza, for support during the Rome fieldwork; and Gordana Fontana-Giusti for advice on urban design. Special thanks are extended to all the participants in the surveys who made this project possible.

Funding information The research was funded by the Academy of Athens, and the travel for the field surveys was covered by the Faculty of Humanities Fund, University of Kent.

Open Access This article is distributed under the terms of the Creative Commons Attribution 4.0 International License (http:// creativecommons.org/licenses/by/4.0/), which permits unrestricted use, distribution, and reproduction in any medium, provided you give appropriate credit to the original author(s) and the source, provide a link to the Creative Commons license, and indicate if changes were made.

\section{References}

Ait-Ameur K (2002) Characterisation of the microclimate in urban public spaces through the validation of a morpho-climatic indicator system.
Design with the environment. In: Passive and low energy architecture conference proceedings, pp 305-311

Aljawabra F, Nikolopoulou M (2009) The influence of hot arid climate on the use of outdoor urban spaces and thermal comfort: do cultural and social backgrounds matter? Intell Build Int 2(3):1-20

Baker N (2001) We are really outdoor animals. In: Moving thermal comfort standards into the 21 st century proceedings. Oxford Brookes University, pp 102-111

Brager GS, de Dear RJ (1998) Thermal adaptation in the built environment: a literature review. Energy Build 27:83-96

Chen L, Ng E (2012) Outdoor thermal comfort and outdoor activities: a review of research in the past decade. Cities. 29:118-125

Google Earth (2013) Rome and London (41 $533^{\prime} 41.42 " N 12^{\circ} 28^{\prime} 29.99 " E$ eye alt $400 \mathrm{~m} \& 51^{\circ} 30^{\prime} 46.82^{\prime \prime} \mathrm{N} 0^{\circ} 07^{\prime} 34.67$ Weye alt $\left.400 \mathrm{~m}\right)$. Google Earth Imagery Date: 6/17/2013. Accessed 25 Nov 2013

Henshaw V, Adams M, Cox TJ (2009) Route planning a sensory walk: sniffing out the issues. In: The 2009 Royal Geographical Society annual conference proceedings, 26-28 august 2009. University of Manchester, Manchester

ISO 7726 (1998) Ergonomics of the thermal environment: instruments for measuring physical quantities. International Standards Organisation, Geneva

Johansson E, Thorsson S, Emmanuel R, Kruger E (2014) Instruments and methods in outdoor thermal comfort studies - the need for standardisation. Urban Clim 10:346-366. https://doi.org/10.1016/j. uclim.2013.12.002

Knez I, Thorsson S (2006) Influence of culture and environmental attitude on thermal, emotional and perceptual evaluations of a square. Int J Biometeorol 50(5):258-268

Lam FK (2012) Simulating the effect of microclimate on human behaviour in small urban spaces. University of California. Phd Thesis, Berkeley

Lenzholzer S, Koh J (2010) Immersed in microclimatic space: microclimatic experience and perception of spatial configurations in Dutch squares. Landsc Urban Plan 95(1-2):1-15

Lenzholzer S, Klemm W, Vasilikou C (2017) Qualitative methods to explore thermo-spatial perception in outdoor urban spaces. Urban Climate in press

Ng E (2012) Towards planning and practical understanding of the need for meteorological and climatic information in the design of highdensity cities: a case-based study of Hong Kong. Int J Climatol 32: 582-598

Nikolopoulou M, Lykoudis S (2007) Use of outdoor spaces and microclimate in a meditteranean urban area. Build Environ 42:3691-3707

Nikolopoulou M, Baker N, Steemers K (2001) Thermal comfort in outdoor urban spaces: understanding the human parameter. Sol Energy 70(3):227-235

Ouameur F, Potvin A (2007) Urban microclimates and thermal comfort in outdoor pedestrian spaces: a dynamic approach assessing thermal transients and adaptability of the users. In: The American Solar Energy Society conference proceedings, Cleveland, pp 12-14 July

Potvin A (2000) Assessing the microclimate of urban transitional spaces. In: PLEA2000 passive and low enegry architecture proceedings. July, Cambridge

Vasilikou C (2015) The role of urban morphology and pedestrian movement in the perception of thermal comfort. University of Kent. [PhD thesis - accessible by request]

Vasilikou C (2018) The doors of dynamic thermal perception: towards environmental quality in urban design. In: Aletta F, Xiao J (eds) Handbook of research on perception-driven approaches to urban assessment and design, IGI Global, p 2018

Vasilikou C, Nikolopoulou M (2013) Thermal Walks: identifying pedestrian thermal comfort variations in the urban continuum of historic city centres. In: Proceeding of PLEA2013 - 29th Conference, Sustainable architecture for a renewable future, Munich, Germany 10-12 September 2013 